\title{
Relation between benign course of multiple sclerosis and low-grade humoral immune response in cerebrospinal fluid
}

\author{
LENA STENDAHL-BRODIN AND HANS LINK \\ From the Departments of Ophthalmology and Neurology, University Hospital, Linköping, Sweden
}

SUMMARY The prognosis in multiple sclerosis (MS) is related to the presence of an abnor ma humoral immune response within the central nervous system: $14 / 17 \mathrm{MS}$ patients $(82 \%)$ without oligoclonal CSF IgG displayed no or slight disability after a mean duration of MS of 17 years, while $53 \%$ of 88 patients with oligoclonal CSF IgG had a benign course after a mean duration of 13 years $(\mathrm{p}<0.05)$. A benign course also was more often accompanied by a normal CSF IgG index. MS patients without oligoclonal CSF IgG had elevated CSF/serum ratios of albumin in $6 \%$, and of the complement factors $\mathrm{C} 3$ in $0 \%$ and $\mathrm{C} 4$ in $6 \%$, as against $20 \%, 27 \%$ and $37 \%$, respectively, in MS patients with oligoclonal CSF IgG.

Protein migrating as bands in the gamma globulin region on electrophoresis of cerebrospinal fluid (CSF) but not serum from multiple sclerosis (MS) patients was suggested by Laterre $^{1}$ to represent an oligoclonal reaction with IgG synthesis within the central nervous system (CNS). The IgG character of electrophoretically separable gamma globulin bands was soon proved, ${ }^{2}$ as was the ability of MS CSF lymphocytes to synthesize oligoclonal IgG in vitro. $^{3}$ The oligoclonal character of CSF IgG in MS has been further documented by demonstration of a restricted heterogeneity of $\gamma$ chains, ${ }^{2}$ an abnormally high kappa to lambda light chain ratio $^{4}$ and predcminance of $\gamma_{1}$ chains. $^{5}$

About $90 \%$ of MS patients display oligoclonal IgG when CSF is studied by electrophoresis on agar $\operatorname{gel}^{2{ }^{6} 7}$ on agarose gel $^{8}$ or by isoelectric focusing. ${ }^{910}$ The number and mobility of oligoclonal IgG bands in the individual MS patient has keen shown to be constant during the course of the disease although the bands may be more or less strong. ${ }^{12}$ We have not encountered a single case in whom the bands have vanished once they have appeared. This observation requires stan-

Address for reprint requests: $\mathrm{Dr} H$ Link, Department of Neurology, University Hospital, S-581 83 Linköping, Sweden.

Accepted 24 October 1979 dardization of CSF electrophoresis regarding amount of IgG applied. ${ }^{8}$ Tourtellotte and $\mathrm{Booe}^{13}$ have shown recently that treatment with ACTH or prednisone reduces the CSF IgG levels but does not eradicate the oligoclonal IgG band pattern.

There is, however, a substantial although small group of patients with clinically definite MS in whom oligoclonal CSF IgG can not be demonstrated. It is not known whether such MS patients differ regarding the course of disease or frequency of other CSF abnormalities when compared with patients with oligoclonal CSF IgG.

\section{Materials and Methods}

One hundred and five consecutive patients (65 females) with MS were studied. Eighty-eight of them had oligoclonal IgG demonstrable in CSF by agarose gel electrophoresis. The diagnosis of MS was made according to the clinical criteria of Müller. ${ }^{11}$ None of the patients was treated with corticosteroids or cytotoxic immunosuppressive drugs for at least six months prior to the investigation.

The patients were classified into two groups regarding disability. Patients who had no or slight disability were able to manage on their own in every respect, while those who had moderate or severe disability were dependent on a variable 
degree of assistance, and their professional and social lives were disturbed.

$15 \mathrm{ml}$ of CSF was obtained by lumbar puncture. A serum specimen was taken simultaneously. CSF leukocytes were counted and differentiated by phase contrast microscopy. The erythrocyte count in CSF did not exceed $100 \times 10^{6} / 1$. IgG and albumin were determined simultaneously in previously unfrozen, unconcentrated CSF and in serum, mostly within 24 hours after lumbar puncture, and the CSF IgG index (see below) was determined. A portion of the CSF was concentrated by ultrafiltration in collodion bags (Sartorius Membranfilter, Göttingen, W. Germany) at $4{ }^{\circ} \mathrm{C}$ to an $\mathrm{IgG}$ concentration of about $3 \mathrm{~g} / 1$ and then analysed by agarose gel electrophoresis in parallel with serum. The remaining unconcentrated CSF was stored at $-20^{\circ} \mathrm{C}$ and then investigated simultaneously regarding IgA, kappa and lambda light chains, and complement factors C3 (beta 1C/beta $1 \mathrm{~A}$ globulin) and C4 (beta $1 \mathrm{E}$ globulin) together with the corresponding serum.

\section{Immunochemistry}

Determinations of albumin, IgG, IgA, and kappa and lambda light chains were carried out on unconcentrated CSF and on serum by an automatic immunoprecipitation technique utilizing nephelometric analyses of antigen-antibody complexes in a continuous flow system (Auto-Analyser II, Technicon Corp., Inc., Tarrytown, N.Y.). The complement factors C3 and C4 were determined by single radial immunodiffusion ${ }^{14}$ mod:fied as described. ${ }^{15}$ Antisera against albumin, IgG, IgA, kappa and lambda Bence Jones protein were purchased from Dakopatts (Copenhagen, Denmark), antiserum against $\mathrm{C} 3$ from Organon Technica (Oss, Holland) and $\mathrm{C} 4$ from Behringwerke (Marburg-Lahn, W. Germany).

The CSF IgG index ${ }^{16}$ equal to the ratio (CSF IgG/serum IgG): (CSF albumin/serum albumin) which takes into account the influence of serum IgG as well as of blood brain barrier disturbances was calculated; an index value above 0.70 which constitutes the upper normal limit in our laboratory is considered to indicate IgG synthesis within the CNS. The IgA concentration in CSF was similarly presented by the CSF IgA index; the upper normal value is $0 \cdot 62$.

The kappa/lambda ratio ${ }^{4}$ was determined. The $95 \%$ confidence limits in our laboratory are 0.7 to 1.7 for CSF and 0.7 to 1.3 for serum.

Agarose gel (Behringwerke) electrophoresis was carried out as described previously. ${ }^{8}$ The occurrence of one or more homogeneous bands in the gamma globulin region in addition to those normally seen was considered abnormal.

\section{Results}

Relation between oligoclonal CSF IgG and clinical variables

Subgrouping of the MS patients according to presence or absence of oligoclonal CSF IgG revealed only a slight difference regarding age at onset, while the mean duration of the disease was somewhat longer in the group without oligoclonal CSF IgG (table 1). Fourteen of the 17 patients $(82 \%)$ without oligoclonal CSF IgG displayed no or slight disability, however, after a mean duration of disease of 17 years, in contrast to $53 \%$ of the patients with oligoclonal CSF IgG after a mean duration of 13 years $\left(p<0.05 ; \chi^{2}\right.$ with Yates' correction for small numbers).

Table 1 Relation between oligoclonal CSF IgG and clinical findings in multiple sclerosis

\begin{tabular}{lll}
\hline CSF abnormality & \multicolumn{2}{l}{ Oligoclonal CSF IgG } \\
\cline { 2 - 3 } & $\begin{array}{l}\text { Present } \\
(n=88)\end{array}$ & $\begin{array}{l}\text { Absent } \\
(n=17)\end{array}$ \\
\hline $\begin{array}{l}\text { Age at onset (mean) } \\
\text { Duration of disease (mean) }\end{array}$ & $\begin{array}{l}30 \text { years } \\
13 \text { years }\end{array}$ & $\begin{array}{l}28 \text { years } \\
17 \text { years }\end{array}$ \\
\hline $\begin{array}{l}\text { Slight or no disability } \\
\quad 61 \text { patients }\end{array}$ & $47(53 \%)$ & $14(82 \%)$ \\
$\begin{array}{l}\text { Moderate to severe disability } \\
44 \text { patients }\end{array}$ & $41(47 \%)$ & $3(18 \%)$ \\
\hline
\end{tabular}

Relation between oligoclonal CSF IgG and other CSF abnormalities

The patients with oligoclonal CSF IgG displayed significantly higher frequencies of elevated CSF IgG index values $\left(\chi^{2}=22.81 ; \mathrm{p}<0.001\right)$, elevated kappa/lambda ratios $(\mathrm{p}<0.05)$ and elevated CSF/ serum $C 4$ ratios $(p<0.05)$ table 2$)$. In contrast, atnormal blcod brain barrier as determined by the CSF: serum albumin ratio, elevated CSF IgA index values, and elevated $\mathrm{CSF}$ : serum $\mathrm{C} 3$ ratios were found at similar low frequencies irrespective of the presence of oligoclonal CSF IgG.

\section{Relation between CSF IgG index and clinical variables}

Table 3 shows that patients with a malignant course of MS only rarely displayed a normal CSF IgG index, in contrast to patients with the most benign course $(p<0 \cdot 001)$. Conversely, the highest CSF IgG index values were observed somewhat more frequently among the patients with a malignant course. Two of the 19 patients, however, with the most benign course displayed CSF IgG index values above $1 \cdot 2$. 
Table 2 CSF findings in 105 multiple sclerosis patients subgrouped according to presence of oligoclonal $\mathrm{IgG}$ in CSF

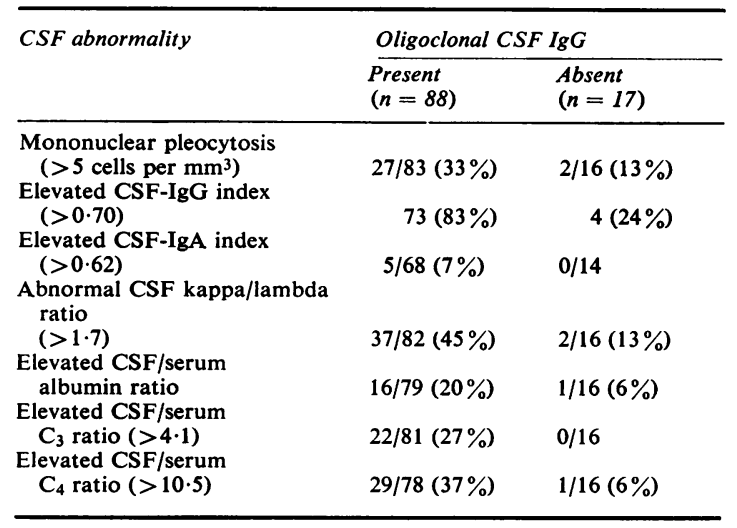

Table 3 Relation between course of multiple sclerosis and CSF $\operatorname{IgG}$ index

\begin{tabular}{lrrrr}
\hline & \multirow{2}{*}{$\begin{array}{c}\text { Number } \\
\text { of } \\
\text { cases }\end{array}$} & \multicolumn{4}{c}{ CSF IgG index } \\
\cline { 3 - 5 } & \multicolumn{1}{c}{$<0 \cdot 7$} & $0 \cdot 7-1 \cdot 2$ & $>1 \cdot 2$ \\
\hline Whole material & 105 & $28(27 \%)$ & $49(46 \%)$ & $28(27 \%)$ \\
Malignant course* & 17 & $2(12 \%)$ & $8(47 \%)$ & $7(41 \%)$ \\
Benign course $\dagger$ & 44 & $15(34 \%)$ & $22(50 \%)$ & $7(16 \%)$ \\
Benign course & 19 & $9(47 \%)$ & $8(42 \%)$ & $2(11 \%)$ \\
\hline
\end{tabular}

* Moderate to severe disability within 5 years after onset.

$\dagger$ Slight or no disability after 10 years.

¥ Slight or no disability after 20 years.

\section{Discussion}

For the demonstration of oligoclonal IgG, electrophoresis of CSF and serum taken simultaneously is usually carried out on a suitable supporting medium, usually agar gel or agarose gel; more recently, commercially available readyprepared agarose gel plates have been used. ${ }^{10}{ }^{17}$ A useful alternative for demonstration of oligoclonal IgG is isoelectric focusing, which can also be performed on commercially available readyprepared thin-layer polyacrylamide gel plates. ${ }^{18}$

Although technical factors may sometimes determine the presence or absence of oligoclonal IgG demonstrable on electrophoresis of CSF, it has been shown that oligoclonal IgG, from its onset of appearance, remained rather constant regarding number and position of electrophoretically separable bands in consecutive CSF specimens from the individual MS patient during the course of disease, at least when agar gel electrophoresis was used as supporting medium. ${ }^{12}$ In contrast, the CSF IgG expressed as percentage of the total protein fluctuated in the individual MS patient between abnormally high values indi- cating IgG synthesis within the CNS, and normal values.

CSF and serum obtained on more than one occasion, covering an observation time of usually more than 3 months, were studied in most of our 17 MS patients who did not display oligoclonal CSF IgG, with the same results. An absent, or less pronounced humoral immune response within the CNS may be anticipated in these patients. This is further strengthened by our finding in this patient group of significantly lower frequencies of abnormal CSF IgG index values and CSF kappa:lambda ratios. However, our data indicate that these two CSF abnormalities may occur in single cases of MS with normal CSF electrophoresis.

The present results indicate that MS patients without oligoclonal IgG in CSF demonstrable by agarose gel electrophoresis, although representing a minority of the patients with this disease, had a better prognosis than patients with oligoclonal CSF IgG. Thus, the grade of the humoral immune response within the CNS seems to be coupled to the prognosis in MS. Similar observations have previously been made when the IgG level in CSF expressed as the percentage of the total protein was considered. ${ }^{19}$ MS patients therefore with the most malignant course (severe disability within 10 years) had elevated CSF IgG levels more frequently than patients with a benign course (no disability after 10 or more years). Although determination of the IgG:total protein ratio of CSF is less reliable compared to the CSF IgG index for demonstration of IgG synthesis within the $\mathrm{CNS},{ }^{20}$ our present findings using the CSF IgG index confirmed the relation between benign course of MS and normal CSF IgG levels, and vice versa.

Electrophoresis of CSF for demonstration of oligoclonal IgG and determination of the CSF IgG index is carried out in neurological patients with suspected MS. Our results indicate that these CSF studies may also be of value for the prognostic evaluation of patients with clinically definite MS.

This investigation was supported by grants from the Swedish Medical Research Council (project no 3381) and the Swedish Multiple Sclerosis Society.

\section{References}

1 Laterre EC. Les protéines du liquide céphalorachidien à l'état normal et pathologique. Bruxelles: Edition Arscia, 1965. 
2 Link H. Immunoglobulin G and low molecular weight proteins in human cerebrospinal fluid: Chemical and immunological characterization with special reference to multiple sclerosis. Acta Neurol Scandinav 1967; 43: Suppl. 28:1-136.

3 Sandberg-Wollheim M, Zettervall O, Müller R. In vitro synthesis of IgG by cells from the cerebrospinal fluid in a patient with multiple sclerosis. Clin exp Immunol 1969; 4:401-5.

4 Link H, Zettervall O. Multiple sclerosis-Disturbed kappa: lambda light chain ratio of immunoglobulin G in cerebrospinal fluid. Clin exp Immunol 1970; 6:435-8.

5 Vandvik B, Natvig JB, Wiger D. IgG 1 subclass restriction of oligoclonal IgG from cerebrospinal fluids and brain extracts in patients with multiple sclerosis and subacute encephalitides. Scand $J$ Immunol 1976; 5:427-36.

6 Laterre EC, Callewaert A, Heremans JB, Sfaello Z. Electrophoretic morphology of gammaglobulin in cerebrospinal fluid of multiple sclerosis and other diseases of the nervous system. Neurology (Minneap) 1970; 20:982-90.

7 Link H, Müller R. Immunoglobulins in multiple sclerosis and infections of the nervous system. Arch Neurol (Chic) 1971; 25:326-44.

8 Link $\mathrm{H}$. Comparison of electrophoresis on agar gel and agarose gel in the evaluation of gammaglobulin abnormalities in cerebrospinal fluid and serum in multiple sclerosis. Clin Chim Acta 1973; 46:383-9.

9 Delmotte P. Etude par focalisation isoelectrique des gammaglobulins du liquide cephalo-rachidien dans la sclerose en plaques et d'autres maladies neurologiques. Université do Poitiers, YER Sciences thèse no 38. 1975.

10 Link H, Laurenzi MA. Immunoglobulin class and light chain type of oligoclonal bands in CSF in multiple sclerosis determined by agarose gel electrophoresis and immuno-fixation. Ann Neurol 1979; 6:107-10.
11 Müller R. Studies on multiple sclerosis. Acta Med Scand 1949; 133: suppl. 222, 1-214.

12 Olsson J-E, Link H. Immunoglobulin abnormalities in multiple sclerosis-Relation to clinical parameters: Exacerbations and remissions. Arch Neurol (Chic.) 1973; 28:392-9.

13 Tourtellotte WW, Booe IM. Multiple sclerosis: The blood-brain barrier and the measurement of de novo central nervous system IgG synthesis. Neurology 1978; 28 (2): 76-83.

14 Mancini G, Vaerman JP, Carbonara AO, Heremans JF. A single radial-diffusion method for the immunological quantification of proteins. In: Peeters $\mathrm{H}$, ed. 11th Colloquium on Protides of the Biological Fluids. Amsterdam: Elsevier, 1964: 370-3.

15 Link H, Zettervall O, Blennow G. Quantification of individual CSF proteins in the evaluation of increased CSF total protein. Z $\mathrm{bl}$ Neurol 1972; 203:119-32.

16 Tibbling G, Link $\mathrm{H}$, Öhman S. Principles of albumin and IgG analyses in neurological disorders. I. Establishment of reference values. Scand J Clin Lab Invest 1977; 37:385-90.

17 Johnson KP, Arrigo SC, Nelson BJ, Ginsberg A. Agarose electrophoresis of cerebrospinal fluid in multiple sclerosis. Neurology 1977; 27:273-7.

18 Laurenzi MA, Link H. Comparison of agarose gel electrophoresis and isoelectric focusing in the demonstration of oligoclonal immunoglobulins in CSF and serum. Acta Neurol Scandinav 1978; 58:148-56.

19 Olsson J-E, Link H, Müller R. Immunoglobulin abnormalities in multiple sclerosis. Relation to clinical parameters: Disability, duration and age of onset. J Neurol Sci 1976; 27:233-45.

20 Link $\mathrm{H}$, Tibbling G. Principles of albumin and IgG analyses in neurological disorders. III. Evaluation of $\operatorname{IgG}$ synthesis within the central nervous system in multiple sclerosis. Scand J Clin Lab Invest 1977; 37:397-401. 


\section{Notices}

12th World Congress of Neurology, 20-25 September 1981, Kyoto, Japan.

Congress Programme

A Main Themes:

(1) Hemispheric Specialisation in Man

(2) Cerebral Vascular Diseases

(3) Neurotransmitter and Neuropeptide Dysfunction in Relation to Neurological Disease

(4) Viral Infections of the Nervous System

B Free Communications

C Technical Exhibition of Medical Equipment, Books and Pharmaceuticals

D Symposia related to Neurology

Official Languages: English, French, German and Spanish

Deadlinc for Submitting Abstracts:

Abstracts must reach the Secretariat not later than 31 December 1980.

Further information can be obtained from:

Secretariat, 12th World Congress of Neurology, c/o Simul International, Inc, Kowa Bldg No 9, 1-8-10, Akasaka, Minato-ku, Tokyo 107, Japan.

International Association for the Study of Pain. Third World Congress. Edinburgh, Scotland, 4-11 September, 1981.
Details may be obtained from the Pain Congress Secretariat, University of Edinburgh, Centre for Industrial Consultancy and Liaison, 16 George Square, Edinburgh EH8 9LD, Scotland, UK.

\section{International Symposium on}

Gilles de la Tourette syndrome

This will be held in New York City 28-29 May 1981 .

Further information may be obtained from: Dr Arnold Friedhoff, Director, Millhauser Laboratories, New York University School of Medicine, 550 First Avenue, New York, NY 10016, USA.

\section{Migraine Symposium}

International Congress of Neurology, Kyoto, Japan, 22 September 1981. Further information may be obtained from: Dr F Clifford Rose, Princess Margaret Migraine Clinic, Charing Cross Hospital, London W6 8RF.

\section{Correction}

In the review of "Muscular Dystrophy and other Inherited Diseases of Skeletal Muscles in Animals" edited by JP Harris (Journal of Neurology, Neurosurgery, and Psychiatry 1980; 43:859) it was incorrectly stated that Alexander Sandow, to whom the volume was dedicated, had died a year before the Symposium was held. In fact, Dr Sandow was a co-organiser of the Conference, helped to bring it to a successful conclusion, and died three months later.

\section{Correction}

The authors of the paper "Relation between benign course of multiple sclerosis and low-grade humoral immune response in cerebro-spinal fluid", Dr Stendahl-Brodin and Dr Link (Vol $43 \mathrm{p}$ 102) wish to draw attention to an error in their calculations. The significance of one result was grossly overrated. The following results are obtained when correctly applying Fisher's exact test. Fourteen of the 17 patients $(82 \%)$ without oligoclonal CSF IgG displayed no or slight disability after a mean duration of disease of 17 years, in contrast to $53 \%$ of the patients with oligoclonal CSF IgG after a mean duration of 13 years $(p<0.05)$. The patients with oligoclonal CSF IgG displayed significantly higher frequencies of elevated CSF IgG index values $(p<0.001)$, elevated kappa/lambda ratios $(p<0.05)$, elevated $\mathrm{CSF} /$ serum $\mathrm{C} 3$ ratios $(\mathrm{p}<0.05)$ and elevated $\mathrm{CSF} /$ serum $\mathrm{C} 4$ ratios $(\mathrm{p}<0.05)$ (table 2). In contrast, abnormal blood brain barrier as determined by the CSF/serum albumin ratio, and elevated CSF IgA index values were found at similar low frequencies irrespective of the presence of oligoclonal CSF IgG.

Table 3 shows that patients with a malignant course of MS only infrequently displayed a normal CSF IgG index, in contrast to patients with the most benign course $(p<0.05)$ 